\title{
Analysis of Location Variability for Wireless Infrared Channel in Inbuilding Environment
}

\author{
Prakash H. Patil and Dilip D. Shah
}

\begin{abstract}
Nowadays, the short range infrared wireless communication has become the most popular technique in In building communication. This paper has been described the modeling of wireless infrared channel by using time domain approach. Impulse response is the most imperative and critical parameter in IR wireless channel modeling. The Non-directed, Non-LOS IR (Diffuse) link configuration is taken into account for the simulation study. Our major attention is to obtain the received signal strength by moving the receiver at different locations in the entire rectangular room and suggest the specific area giving the maximum strength of the received signal. In order to perform this task of receiver location variability, the simulation analysis is carried out with the help of the three dimensional (3-D) plot.
\end{abstract}

Index Terms-IR wireless, IM/DD channel, Location variability, Multipath Impulse response.

\section{INTRODUCTION}

The number of personal computers and personal digital assistants for indoor use are rapidly growing in offices, manufacturing floors, shopping areas and warehouses. In near future, one will find very often several such devices clustered within small indoor areas. This will result in the need for flexible interconnection through the distributed or centralized data communication systems. The traditional way to meet this requirement is to use wired physical connections. But, wired physical connections have some inherent problems, in setting up and in its expansion. Further, these need more space, time to setup, monetary investment in copper, maintenance etc. Wireless systems offer an attractive alternative. Both, radio frequency (RF) and infrared (IR) radiation are possible options in implementing wireless systems. Unfortunately, the RF can support only limited bandwidth because of restricted spectrum availability and interference; while this restriction does not apply to IR. Thus, optical wireless (IR) technology [1] seems to be ideal for wireless communication systems of the future. It can provide cable free communication at very high bit rates (a few Gbps as compared to tens of Mbps supported by radio). In indoor optical wireless systems, laser diodes (LDs) or light emitting diodes (LEDs) are used as transmitter and photo-diodes as the receivers for optical signals. These opto-electronic devices are cheaper as compared to RF equipment as well as

Manuscript received November 23, 2012; revised July 28, 2013

Prakash H. Patil is with Indira College of Engineering, University of Pune, India (e-mail: phpatil2005@yahoo.co.in). India. wire line systems. Further, IR transmission does not interfere with existing RF systems and is not governed by Federal Communications Commission (FCC) regulations. The IR signal does not penetrate walls, thus providing a degree of privacy within the office area. In addition to privacy, this feature of IR systems makes it easier to build a cell-based network. For example, in an office building each room would be a cell and there would be no interference between the cells. Therefore, all units can be identical in a cellular architecture as compared to RF configuration in which the operating frequencies of neighboring cells have to be different. Due to the above reasons, optical wireless systems are becoming more popular in various operating environments, such as houses (consumer electronics), offices, medical facilities, manufacturing plants, and business establishments.

\section{IN BUILDING INFRARED IR WIRELESS CHANNEL}

When an infrared signal is incident on an ideal Lambertian reflector, it will radiate in all directions. An infrared wireless communication system exploits this property to send and receive data in an indoor environment. The features of a room, for example, walls, ceiling, and office materials, can be approximated as an ideal Lambertian reflector. The Nondirected optical wireless link (the most practical link) has been investigated and simulated in [2], [3]. Normally, an optical wireless system adopts an intensity modulation and direct detection technique (IM/DD) because of its simple implementation. In an optical system, an optical emitter and a large-area photo detector are used as the transmitter and receiver, respectively. The output current $y(t)$ generated by the photo detector can be written as

$$
Y(t)=r X(t) \otimes h(t)+N(t)
$$

where $\otimes$ denotes convolution, $R$ is the photo detector responsively (in $\mathrm{A} / \mathrm{W}$ ), and $h(t)$ is the channel impulse ambient light, can be modeled as white Gaussian

Noise, it cannot be negative and must satisfy eye safety regulations and is given by the relation as in [2].

$$
X(t) \geq 0
$$

$$
\lim _{T \rightarrow \infty} \frac{1}{2 \pi} \int_{-T}^{T} X(t) d t . \leq P_{a v g}
$$

where

$P_{a v g}=$ the average optical-power constraint of the light emitter.

The advantage of using IM/DD is its spatial diversity. An 
optical system with a large square-law detector operates on a short wavelength which can mitigate the multipath fading. Since the room configuration does not change, the infrared wireless link with IM/DD could be considered as a linear time-invariant channel.

The ceiling-bounce model, as exposed in Fig. 1, developed by Carruthers and Kahn and is given by the reference number as in [2], is selected as the channel model in this paper since it is the most practical and represents the multipath dispersion of an indoor wireless infrared channel accurately. The channel model is characterized by two parameters, rms delay spread $D_{r m s}$ and optical path loss $H(0)$ which cause Intersymbol interference (ISI) and signal attenuation, respectively. The impulse response of an infrared wireless link can be represented as

$$
h(t)=H(0) \frac{6 a^{6}}{(t+a)^{7}} u(t)
$$

where

$u(t)=$ is the unit step function.,

The value of $a$ depends upon the room dimension and locations of the transmitter and the receiver. If both transmitter and receiver are co-located then we have,

$$
a=2 H / c
$$

here

$$
\begin{aligned}
& H=\text { Height of the ceiling } \\
& c=\text { Speed of the light }
\end{aligned}
$$

The parameter $a$ related with the delay spread. $D_{r m s}$ and is given by the expression,

$$
D_{r m s}=\frac{a}{12} \sqrt{\frac{13}{11}}
$$

\section{Multiple Path IMPUlse ResPonse}

In case of diffuse systems the transmitted signal gets reflected from many reflecting surfaces inside the room and finally reaches at the receiver. Hence it is necessary to estimate the impulse response for these multiple paths from IR transmitter reflecting surfaces and receiver. In our research, we have considered multiple bounce impulse response of infrared signal from transmitter to receiver. The algorithm for calculating a multiple bounce impulse response is explained in the next section and is followed by computer implementation by reference number as in [3]. The characterization of IR channel in indoor environment for various transceiver conditions is described by the reference number as in [4]. The experimental analysis of an impulse response for Nondirected IR wireless indoor channel is reported by the reference number as in [5].

\section{A. Location Variability Analysis of Nondirected IR Wireless Channel}

For a given a transmitter T and receiver $R$ in a room with reflectors, light from the transmitter can reach the receiver after any number of reflections. It can be expressed as an infinite sum:

$$
h(t ; S, R)=\sum_{q=0}^{\infty} h^{(q)}(t ; S, R)
$$

where

$$
h^{(q)}(t)=\text { the response of the light undergoing exactly } q
$$
reflections.

The line-of-sight response $h^{q}(t)$ for $q=0$ is estimated by equation (4)

$$
\begin{aligned}
& h^{(0)}(t ; S, R) \\
& \approx \frac{(n+1)}{2 \pi} \cos ^{n}(\phi) d \Omega \operatorname{rect}(\theta / F O V) \delta(t-R / c),
\end{aligned}
$$

For the higher-order reflections $(q>0)$ the impulse response can be calculated by recursion as given below [4] [5].

$$
\begin{array}{r}
h^{q}(t ; T ; R)=\int_{S} h^{(0)}(t ; T\{r, \hat{n}, \pi / 2, d A\}) \\
\otimes \boldsymbol{h}^{(q-1)}(t ;\{r, \hat{n}, 1\}, R)\left[\frac{\rho_{i} \cos ^{n}(\phi) \cos (\theta)}{d^{2}}\right]
\end{array}
$$

where

$\otimes=$ Convolution .

$T=$ Transmitter, $R=$ Receiver.

$q=$ Number of reflection,

Now, $h^{q}(t)$ is estimated by the expression given below.

$$
\begin{gathered}
h^{(q)}(t: T, R) \approx \sum_{i=1}^{N} h^{(0)}\left(t ; T, \mathcal{E}_{i}\right) \otimes\left(t ; \mathcal{E}_{i}, R\right) \\
=\frac{n+1}{2 \pi} \sum_{i=1}^{N} \int_{S} \frac{\rho_{i} \cos ^{n}(\phi) \cos (\theta)}{R^{2}} \operatorname{rect}(2 \theta / \pi) h^{q-1} \\
(t-R / C ;\{r, \hat{n, 1}\}, R) \Delta A
\end{gathered}
$$

where $\varepsilon_{i}$ represents $i$ th and $N$ indicates the number of elements. $(n+1) / 2 \pi=$ coefficient which decides that the integration of $R(\phi)$, over the surface of the hemisphere resulting the transmitted power $\boldsymbol{P}_{T}$.

Naturally, it is further observed that the q-bounce impulse response from a single point-source $\mathrm{T}$ can be found in two steps:

1) Finding the distribution and timing of the power from $T$ onto the reflecting ceiling.

2) Using the ceiling as a distributed light Source, computing the $(q-1)$ bounce

The simulated code for the estimation of $q$ bounces impulse response numerically and is described. The basic impulse response up to three reflections and the effect of the transmitter eight, different pattern modes on the received power is also reported by the reference number as in [6]. 


\section{B. Location Variability Analysis of Nondirected IR Wireless Channel}

This is one of the new approaches to analyze the Nondirected IR wireless channel in indoor environment.

Fig. 1 shows the transmitter (T) and the receiver (R) geometry inside the empty rectangular room to perform the location variability analysis of Nondirected IR wireless channel.

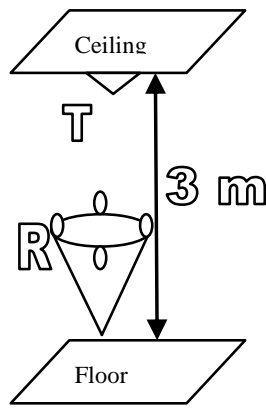

Fig. 1. Transmitter and receiver geometry in empty room.

The transmitter is pointed down while the receiver is pointed up The room dimension is $5 m \times 5 m \times 3 m$ The transmitter is initially located at a height of $2.0 \mathrm{~m}$ and further its height is varied from $2.0 \mathrm{~m}$ to $3.0 \mathrm{~m}$. in steps of $0.5 \mathrm{~m}$ (i. e. $2.0 \mathrm{~m}, 2.5 \mathrm{~m}, 2.75 \mathrm{~m}$ and $3.0 \mathrm{~m}$.) The receiver is located at the desktop height of 1.0 from floor and is moved along both the length and width of the given room dimensions.

\section{Simulation Parameters}

Table I describes the details of simulation parameters for a given room scenario which are required to perform the
Simulation of non directed infrared wireless channel in that room.

TABLE I: ROOM SCENARIO WITH SIMULATION PARAMETERS

\begin{tabular}{|l|l|c|}
\hline \multicolumn{2}{|l|}{ Parameter/configuration } & $\begin{array}{l}\text { Room } \\
\text { Scenario }\end{array}$ \\
\hline Rom Dimension & Length $(\mathrm{X})$ & 5 \\
& Width Y) & 5 \\
& Height $(\mathrm{Z})$ & 3 \\
\hline Reflectivity $(\rho)$ & Wall Ceiling, Floor & 0.6 \\
& & 0.6 \\
& & 0.6 \\
\hline Transmitter $\left(\mathrm{T}_{\mathrm{x}}\right)$ & Mode & 1 \\
& $\mathrm{X}$ & 4 \\
& $\mathrm{Y}$ & 2.5 \\
& $\mathrm{Z}$ & 3 \\
\hline Receiver & Area & 1 \\
$\left(\mathrm{R}_{\mathrm{x}}\right)$ & FOV & $80^{0}$ \\
& $\mathrm{X}$ & 4 \\
& $\mathrm{Y}$ & 2.5 \\
& $\mathrm{Z}$ & 1 \\
\hline
\end{tabular}

The mean, standard deviation and variance is estimated for the analysis of receiver location variability and is listed in Table II. as given below.

\section{Simulation Results}

The simulation results showing 3-D plots are shown below in Fig. 2. Here we showed only three plots for Simplicity by considering the transmitter height near to the ceiling i.e. $2.75 \mathrm{~m}$. Table II describes the values of mean, standard deviation and variance Up to third order reflection along with the variation of the transmitter height from $2.0 \mathrm{~m}$. to $3.0 \mathrm{~m}$ in steps of $0.5 \mathrm{~m}$.

TABLE II. MEAN. STD. DEVIATION AND VARIANCE FOR THREE REFLECTIONS WITH DifFERENT TRANSMITTER HEIGHTS

\begin{tabular}{|c|c|c|c|c|c|c|c|c|c|}
\hline & \multicolumn{3}{|c|}{ Reflection 1 } & \multicolumn{3}{c|}{ Reflection 2 } & \multicolumn{3}{c|}{ Reflection 3 } \\
\hline $\begin{array}{c}\text { Transmitt } \\
\text { er Height }\end{array}$ & Mean & $\begin{array}{l}\text { Standard } \\
\text { deviation }\end{array}$ & Variance & Mean & $\begin{array}{l}\text { Standard } \\
\text { deviation }\end{array}$ & Variance & Mean \\
\hline 3 & -62.6980 & 0.0776 & .0185 & -64.9922 & 0.0527 & 0.0061 & -65.2243 & 0.0574 & 0.0077 \\
\hline 2.75 & -64.6187 & 0.0705 & .0153 & -65.9780 & 0.0671 & 0.0109 & -65.4278 & 0.0787 & 0.0173 \\
\hline 2.5 & -64.3473 & 0.0728 & .0171 & -65.9336 & 0.0618 & 0.0103 & -65.0927 \\
\hline 2 & -65.0657 & 0.0791 & .0203 & -66.2974 & 0.0796 & 0.0170 & -66.3796 & 0.0827 \\
\hline
\end{tabular}

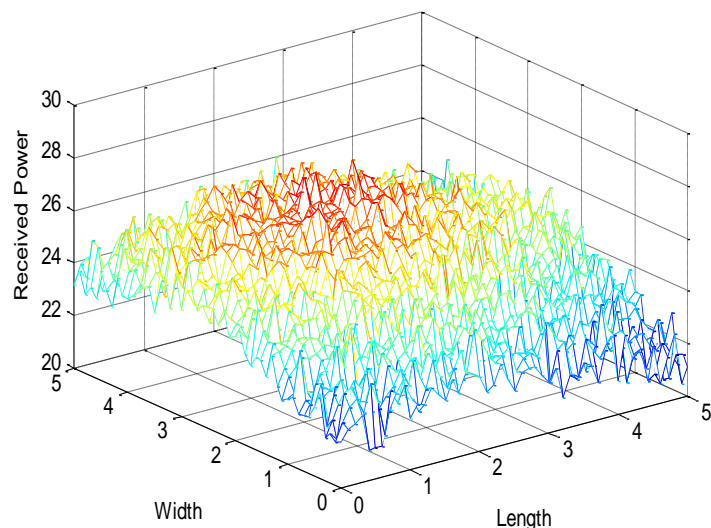

(a)

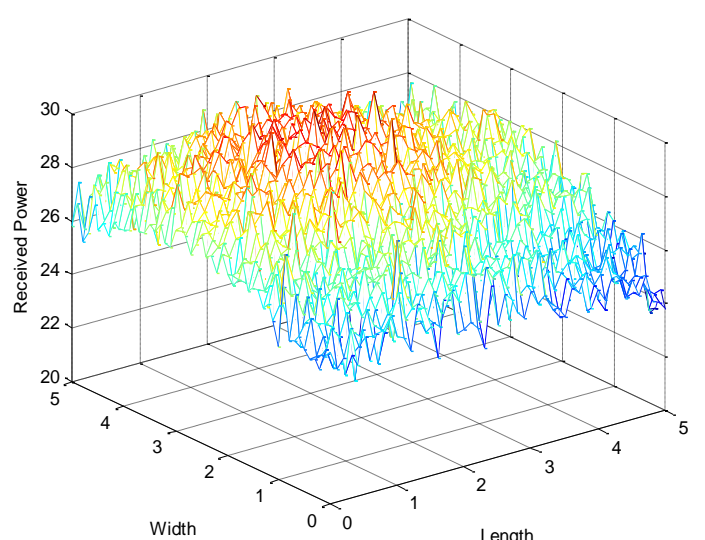

(b) 


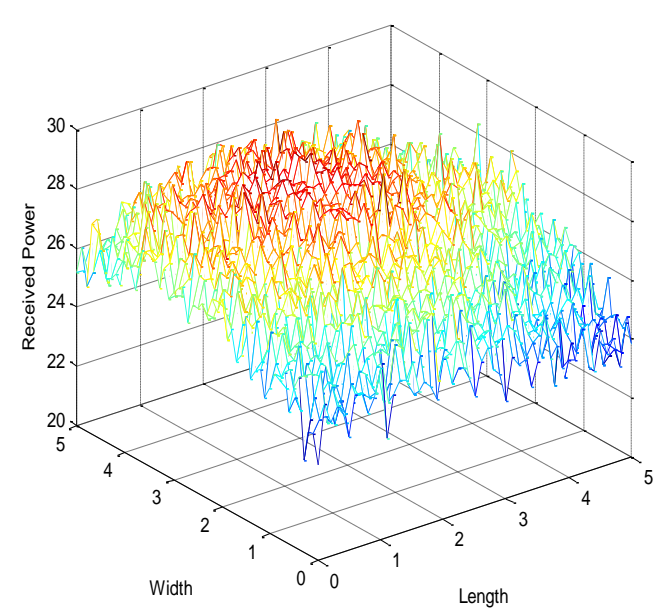

(c)

Fig. 1. Location variability 3-D plots: (a) Transmitter height of $2.75 \mathrm{~m}$. with first order reflection. (b) Transmitter height of $2.75 \mathrm{~m}$. with second order reflection (c) Transmitter height of $2.75 \mathrm{~m}$. with third order reflection

\section{DISCUSSION ON RESULTS}

From the three dimensional (3-D) plots as shown in figure 2 , and table 1 ,it is noticed that for the first order reflection 1 , the mean received power varies from -62.69 to-65.06. Similarly, for the second order and third order reflection, the mean received power variation is from -64.99 to -66.29 and -65.09 to -66.37 respectively. The variation of standard deviation and variance is extremely small and hence ignored. From these plots it is observed that the non-directed IR wireless channel modeling with third order reflection provides the superior results. The position of the transmitter near the ceiling at $2.75 \mathrm{~m}$ is the optimum value for the different radiation pattern modes

\section{CONCLUSION}

From the simulation analysis performed above it is concluded that the maximum signal strength at the receiver is obtained if the transmitter is located at a height of $2.75 \mathrm{~m}$. near the ceiling and the receiver is located at a height of $1 \mathrm{~m}$, from the floor and at the room centre. Also from the 3-D plots it is further concluded that if the receiver is located in red color zone it provides the higher signal strength. While in blue zone it provides the considerably lower signal strength. Thus for the given fixed In-building scenario and the specific transmitter receiver geometry inside the room, we can suggest the area for the optimum location of the receiver for a particular room environment giving the maximum and meaningful signal strength.

\section{ACKNOWLEDGMENT}

The authors wish to thank the anonymous reviewers. The authors greatly acknowledge Dr. R. V. Kshirsagar, Vice Principal and Head Priyadarshini College of Engineering, $\mathrm{PhD}$ Research Centre, for giving opportunity to perform this research work. The authors also admit the cooperation and support from Hon. Dr. Tarita Shankar, chairperson, Shri Chetan Wakalkar, group director, Indira Group of Institutes (IGI), Mr. Adesh Gaekwad, executive director and Dr. R. V. Kulkarni, director Indira College of Engineering and
Management Pune

\section{REFERENCES}

[1] F. R. Gfeller and U. H. Bapst, "Wireless in-house data Communication via diffuse infrared radiation," in Proc. IEEE, vol 67, no. 11, pp. 1474-1486, 1979.

[2] J. B. Carruthers and J. M. Kahn, "Modeling of nomndirected wireless infrared channels," IEEE Trans.Commnication, vol. 45, no.10, pp. 1260-1268, 1997.

[3] J. R. Barry, J. M. Kahn, W. J. Krause, E. A. Lee, and D. G.Messerschmitt, "Simulation of multipath impulse response for indoor wireless optical channels," IEEE Jl. Select. Areas in Commun. vol. 11, no. 3, pp. 367-379, 1993.

[4] C. Peng and J. K. Pan, "Channel Characteristics for Indoor Wireless Infrared Communication System due to Different Transceiver Conditions," Journal of KICS, vol. 33, no. 2, pp.198-03, February 2008.

[5] J. M. Kahn, W. J. Krause et.al, "Experimental characterization of nondirected indoor infrared channels," IEEE Trans. on communication, vol. 43, no. 2/3/4, pp. 1613- 1623. Feb/Mar/April, 1995.

[6] P. H. Patil and D. D. Shah, "Performance analysis and channel characterization of indoor infrared wireless communication system," in Proc. 3 rd Intl. Conf. on Electronics and Computer Technology (ICECT-2011), Kanyakumari, April-2011, pp. 89-93.

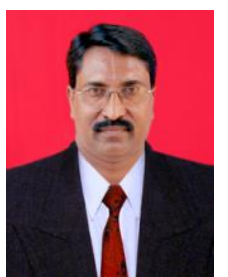

Prakash H. Patil has born in Kolhapur, Maharashtra state (India). His date of birth is July, 4, 1963. He has completed B.E(Electronics) from KIT's College of Engineering, Kolhapur affiliated to Shivaji University Kolhapur in year 1990 and M.E. (Electronics) in year 2000, from Walchand College of Engineering Sangli affiliated to the same University. He is presently pursuing for Ph.D. in Electronics Engg. at

Priyadarshini college of engineering Nagpur, affiliated to University of Nagpur.

He has total 22 years of experience in R\&D/Teaching. He has worked as lecturer and Assistant Professor and the department Head for Undergraduate program in Engineering. Currrently, he is working as the Associate Professor in Department of Electronics and Telecommunication Engg. at Indira College of Engineering and Management Pune. He has published 35 Research Papers in International /National journals and conferences His area of interest includes mobile communication, Telematics, Optical communication, Computer networks and Optical wireless communication. Mr. Prakash is the Life Member of Indian Society for Technical Education (ISTE). Also, he was IEEE Member of Communication society and Photonics Society for one year He is the Executive Committee Member of the Institution of Electronics and Telecommunication Engineers, Pune centre. He has worked at various committees of administration and academics at University and Institute level.

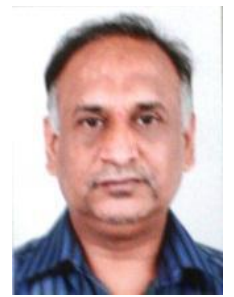

Dilip D. Shah has born in Maharashtra, India. He has completed M.E. (Electronics) from Walchand College of Engineering, Sangli, affiliated to Shivaji University, Kolhapur. He has completed his $\mathrm{PhD}$, from IIT Mumbai in year 2003 and his research area was Fiber optic Communication.

$\mathrm{He}$ has total 35 years of experience in R\&D/Teaching. He worked as the Lecturer, Assistant Professor, and Head of Electronics Engineering Department and Principal at KIT's College Engineering, Kolhapur. He worked as Principal at Priyadarshini college of Engineering Nagpur. Presently, he is working as the Principal at G. H. Raisoni Institute of Engineering, Pune. He has published 60 plus Research Papers in International /National journals and conferences. His area of interest includes Digital Signal Processing, communication, Fiber Optics Communication and Optical wireless communication.

Dr. Dilip is the Life Member of Indian Society for Technical Education (ISTE). Also, he is the member of many other professional bodies. Currently, he is working as the member of the Academic Council, University of Pune. $\mathrm{He}$ has worked in various administrative and academic committees at Institute, University, and National and International level. 